WISSENSCHAFTSZENTRUM BERLIN FÜR SOZIALFORSCHUNG

SOCIAL SCIENCE RESEARCH

CENTER BERLIN

Kai A. Konrad *

Kjell Erik Lommerud **

Love and Taxes - and Matching Institutions

* WZB

** University of Bergen

SP || $2008-04$

February 2008

ISSN Nr. $0722-6748$

Research Area

Markets and Politics

Research Unit

Market Processes and Governance
Schwerpunkt

Märkte und Politik

Abteilung

Marktprozesse und Steuerung 
Zitierweise/Citation:

Kai A. Konrad and Kjell Erik Lommerud, Love and Taxes and Matching Institutions, Discussion Paper

SP II 2008 - 04, Wissenschaftszentrum Berlin, 2008.

Wissenschaftszentrum Berlin für Sozialforschung $\mathrm{gGmbH}$,

Reichpietschufer 50, 10785 Berlin, Germany, Tel. (030) 25491 - 0

Internet: www.wzb.eu 


\section{Love and Taxes - and Matching Institutions}

by Kai A. Konrad and Kjell Erik Lommerud *

We study a setting with search frictions in the marriage market and with incomplete contracting inside the family. Everyone prefers a partner that has high income and is a perfect emotional match, but compromises must often be struck. A high income earner may abstain from marrying a low-income earner even though they would be a perfect match emotionally, because the highincome earner may dislike the implicit income redistribution implied by the marriage. Redistributive income taxation may ease this problem. Income matching institutions that secure that people largely from the same income groups meet each other can substitute for redistribution, so that optimal redistribution is reduced. We also introduce a divorce option. Redistributive taxation is shown both to further and stabilize marriage.

Keywords: Marriage, optimal taxation, emotional rents, love, incomplete contracts, assortative mating, divorce

JEL Classification: H21, J12, D61

* We have benefitted from comments from Friedrich Breyer, Salmai Qari, Ray Rees, Ulrike Schneider, David Soskice, and participants at a workshop on social policy at the IAB in Nuernberg, the 2007 ESPE conference at the University of Illinois, Chicago, and at seminars at Statistics Norway, the University of Hannover and the Norwegian School of Economics. The usual caveat applies. Konrad gratefully acknowledges financial support by the Anglo-German Foundation and Lommerud acknowledges support from the Norwegian Research Council. 


\section{Love and Taxes - and Matching Institutions}

Wenn Menschen mit unterschiedlichem Einkommen heiraten, führt dies zu einer Umverteilung innerhalb der Ehe von der wirtschaftlich stärkeren zur wirtschaftlich schwächeren Person. Zwei Personen, die zufällig aufeinander treffen und aufgrund ähnlicher Interessen und Neigungen gut zueinander passen, werden auch die finanziellen Folgen einer Heirat berücksichtigen. Falls die Person mit hohem Einkommen diese Umverteilung als zu stark empfindet, kommt die Ehe nicht zustande. Die Rente, die z.B. dadurch entsteht, dass das Paar ähnliche Interessen hat oder gemeinsamen Hobbys nachgehen kann, geht in diesem Fall verloren. Progressive Besteuerung führt zu einer Angleichung der Einkommensverteilung und verringert daher die Wahrscheinlichkeit, dass Ehen aufgrund hoher Einkommensunterschiede nicht zustande kommen. Aus wohlfahrtstheoretischer Sicht ist dies ein positiver Aspekt umverteilender Besteuerung, der bisher in der Literatur nicht berücksichtigt wurde. Die optimale Höhe der Besteuerung hängt von den "Matching-Institutionen" ab, d.h. davon wer wen auf dem Heiratsmarkt trifft. Treffen vorwiegend Personen mit unterschiedlichem Einkommen und ähnlichen Interessen aufeinander, ist der positive Effekt der Besteuerung besonders wirksam. In diesem Fall ist der optimale Steuersatz umso höher, je ähnlicher die Interessen der potentiellen Partner ist. Umgekehrt kann progressive Besteuerung in einer Gesellschaft, in der vorwiegend Personen mit ohnehin ähnlichem Einkommen aufeinandertreffen, kaum etwas bewirken. Daher fällt in diesem Fall der optimale Steuersatz umso geringer aus, je ähnlicher die Einkommen der potentiellen Paare auf dem Heiratsmarkt sind. 


\section{Introduction}

When King Edward VIII and Wallis Simpson married, this was seen as a love-marriage. King Edward VIII lost power, status and wealth, but must have gained along some other dimensions, which probably included emotional rents. In terms of status or income, the couple was not a perfect match, but in terms of their preferences and emotions, the match was seemingly excellent. The gains from marrying and becoming the Duke and the Duchess of Windsor must have overcompensated Edwards' material loss. Had Edward's affection for Wallis been potentially still large, but smaller than his material loss, he might have preferred his job as King of Britain. Both had sacrificed the benefits of what is considered a happy marriage.

We consider the role of income differences and "match quality" for marriage decisions in a framework with frictions in the process of assortative matching and with incomplete marriage contracts. The redistributional consequences of marriage are a potential source of efficiency losses in marriage matching markets. People who would be a good match in terms of their consumption preferences, in terms of emotional attachment, or because they share some feelings of love and romantic mutual attachment, have to consider the financial implications of entering into marriage. If the match is very good and the emotional benefit of being together is sufficiently high, they may dominate the negative fiscal implications which one of the spouses may incur. ${ }^{1}$ Given everything else constant, differences in income or productivity, together with the redistributional implications of marriage, make it less likely that two randomly matched persons will marry. ${ }^{2}{ }^{3}$ Redistributive income taxation will be generically beneficial in this context, even though it creates some distortions

\footnotetext{
${ }^{1}$ Empirically, the role of "love" in marriage decisions is the topic of research in other social science disciplines which studies intercultural differences in the importance of "love" for marriage decisions (see, e.g., Levine et al. 1995, and Sprecher et al. 1994)

${ }^{2}$ Wong (2002), for instance, presents evidence for this. She shows that wage is a desirable trait in predicting 'marriageability'. Ermisch, Francesconi and Siedler (2006) surveys some of the literature that documents the empirical importance of mating assorted along the dimensions of income and socio-economic status.

${ }^{3}$ Production of offspring is, of course, another important driver of marriage, as has been argued convincingly by Edlund $(1999,2006)$. This particular aspect is disregarded here, as it is orthogonal to the aspects we consider. Production of offspring cannot, however, be the only motivation for individuals to marry. There are marriages with female partners who passed their fertility age, marriages with male partners who voluntarily underwent sterilization and marriages between homosexual couples. These are difficult to explain on the basis of a desire to reproduce. We think that the factors that influence marriage decisions in these cases are also relevant factors for marriage decisions for couples who are planning to have offspring.
} 
in the labor market: redistributive taxation equalizes individuals' incomes as singles, and therefore reduces the efficiency problem of ex ante heterogeneity of matched partners.

Our main results are on the importance of taxes as a possible means to improve the matching outcome in marriage markets with different types of matching institutions. Some institutions make it more likely that individuals with similar incomes are matched. For instance, school tracking selects children according to their abilities and their family background, and clubs and associations with membership fees sort individuals along income or earnings abilities. We refer to these institutions as income matching. Other institutions improve the matching by making it more likely that individuals with congruent or complementary preferences are matched. We refer to these as preference matching institutions. For instance, when people choose their leisure activities, they typically cluster along their preferences. Two persons who run into each other at a Rolling Stones concert are both likely to like rock music, and people who meet at the Royal Opera House are likely to share some other preferences as regards music. ${ }^{4}$ We show that the role of redistributive taxation is limited, if the existing matching institutions in a country provide good income matching. Intuitively, income matching institutions reduce or eliminate the market failure in matching markets that is caused by income inequality of matched individuals. However, preference matching institutions increase the probability that individuals with different incomes but with highly similar preferences meet and decide whether to marry. We show that strong preference matching strengthens the role of redistributive taxation as an efficiency enhancing policy tool. Hence, income matching institutions and redistributive taxation are strategic substitutes, but preference matching institutions and redistributive taxation are strategic complements.

Fernandez, Guner and Knowles (2005) have a starting point that is similar to ours. They see marital sorting, as we do, as a compromise between love and money. Their particular focus is on the regeneration of inequality in societies with high skill premia. Because inequality is high, the rich will

\footnotetext{
${ }^{4}$ In a series of articles, for example 18.11.2007, the Norwegian newspaper VG covered friendship ties and matching institutions among rich young Norwegians, with an emphasis on Oslo. They first used friendship lists from Facebook to recontruct a large network of friends among the young rich. Then they interviewed network members about how friendships were formed and how matching took place. Choice of sports (alpine skiing and tennis rather than soccer), choice of high school, high school graduation celebrations, and certain social events, as the so-called Roccocco ball, where mentioned as meeting places. This also shows that in an egalitarian society as Norway, where preference matching perhaps is common, there may still be smaller groups, as the ultra-rich, that see the need for income matching institutions.
} 
marry the rich, and the poor are left with each other. In turn, this could imply that some households are cash constrained when it comes to investing in children's education. In this way a society can be trapped in an inequality trap. Our emphasis is on tax policy in a situation in which potential spouses are willing, to some extent, to sacrifice love for money. Redistributive taxation tends to make love cheaper, but the precise policy prescription depends on the matching institutions in a society. The two types of matching institutions may be of different importance in different countries or in different periods of history. ${ }^{5}$ Both types of institution make marriage for given matches generally more likely (compared to a pure random matching), but the first type of institution tends to induce marriage between individuals with similar incomes, and the second type of institution makes marriage between individuals with high income differences more likely. These effects are strengthened if the redistributional tax is chosen that is optimal given the respective matching institutions. Seen from the perspective of income groups, the rich prefer income matching institutions, whereas the poor prefer preference matching institutions. However, redistributive taxation - as mentioned - is most important in societies with preference matching. Perhaps economic analysis is not the right tool to predict how marriage matching institutions come about, but we see the contours of an argument why high-inequality income-matching societies can coexist with low-inequality preference-matching societies, as both types of society go some different ways towards solving the problems described here associated with frictions in the household formation process.

In a further step we allow for uncertainty about the quality of a given match at the point of potential marriage, and for divorce. A divorce option has interesting properties in matching markets, and one of the counter-intuitive results on divorce has been highlighted by Chiappori and Weiss (2006) who show that high divorce rates may improve the performance of the matching markets for remarriage. As we do not consider remarriage, our analysis is different. We ask what the role of divorce cost for marriage and divorce decisions is, if the quality of a given match is still uncertain at the point of marriage while the true quality can be assessed once the marriage has taken place. Marriage has an option value in this case, but, due to the divorce cost, marriage also has some lock-in effect. We show that while the stronger partner in a given match benefits from low divorce cost a positive divorce cost may increase welfare. Our

\footnotetext{
${ }^{5}$ As shown in Ermisch, Francesconi and Siedler (2006), for instance, who analyse the implications of assorted mating for intergenerational income mobility, Germany has a higher degree of assortative mating along the dimensions of income and socio-economic status than the UK in the 1990ies. They mention that early educational tracking may be the key driver of this difference.
} 
emphasis is on the interaction between taxation and divorce cost. We show that taxation makes it less likely that a given couple will be divorced, and may also increase the likelihood of marriage for given marriage institutions.

To study the mentioned effects we remove many other interesting aspects from the analysis. We use a crude matching framework that preserves and emphasizes the frictions in dynamic matching frameworks: each individual meets only one possible partner. ${ }^{6}$ This preserves the characteristics of frictions that has been studied in matching frameworks if the frequency of new mating partners showing up is not infinite and also removes some interesting properties of matching markets from the picture that cannot develop in a one-shot matching market. ${ }^{7}$ Our framework could be extended to a dynamic matching market with repeated matches. The static approach is suitable, however, for considering ex ante heterogeneity plus match specific heterogeneity and it is rich enough to study the interaction of taxation and the quality and characteristics of the matching process. If assortative matching is not frictionless, ex ante heterogeneity of matched partners will result in inefficiency as regards the appropriation of the match specific benefits: partners with high earning ability will refuse matches with partners with low earning ability even if the match has high match specific benefits. This basic inefficiency and a role of redistributive taxation also emerges in more complex, repeated matching problems. ${ }^{8}$ Also, we apply a stylized framework for describing decisions within a marriage. It is important for the subject of our analysis that marriage leads to some income distribution between the spouses within a marriage, and we pursue a benchmark for which this income redistribution yields to egalitarian consumption inside the marriage. This egalitarian outcome is for analytical simplicity only. The theory of the family has emphasized that marriage contracts are genuinely incomplete, and are therefore likely to lead to redistribution inside the marriage. Because many goods consumed in a

\footnotetext{
${ }^{6}$ This implies that the "problem with marriage" will tend to be that people choose to live alone to avoid suffering the redistribution effects of marriage. In a broader model, this would probably translate to a problem of people settling for marrying others that they love only a little, and forego marriages with more love but also more redistribution.

${ }^{7} \mathrm{~A}$ large literature has emerged that studies the dynamics and equilibrium in search and matching markets with two-sided search with either ex ante heterogeneity or match specific heterogeneity (see, e.g., Burdett and Coles 1999).

${ }^{8}$ Empirically, the implications of taxation for marriage have attracted some attention. Several studies consider the financial implications that marriage has for a couple's joint income, and how these implications affect the decision whether to marry (Feenberg and Rosen, 1994, Alm and Whittington 1995). Whether, and how, redistributive income taxation and its income equalizing effect affects the turnover in the marriage market is, so far, an open question.
} 
family are non-rival and/or non-exclusive between family members, marriage between people whose income and productivity skills are not the same will typically involve redistribution of income within the family. This is true for all the major economic approaches in the literature that analyse the family. In Becker's (1981) version of the family with a benevolent dictator who receives all family income and allocates it altruistically among the family members, this fact is the basis of, for instance, Becker's rotten-kid theorem. In the noncooperative family introduced by Lundberg and Pollak (1993) and Konrad and Lommerud (1995), family members contribute income to a family public good non-cooperatively. As is well known from the literature on the private provision of public goods (Bergstrom 1989), such contribution links exert strong redistributional pressure. ${ }^{9}$ Finally, also in approaches that describe the family as an efficient bargaining framework in which the threat point of negotiations is the non-cooperative equilibrium, the redistribution that emerges in the threat point outcome spills over to the cooperative bargaining outcome (see, e.g., Konrad and Lommerud 2000, Lundberg and Pollak 2003).

We consider the optimal linear income tax in a framework in which the government does not have any redistributional preferences per se and determine the optimal linear tax that trades off the negative incentive effects in the labor market and the positive effects on the marriage decisions. This reveals a new beneficial aspect of redistributive income taxation that adds to the beneficial effects that have been found in the context of status preferences (Corneo 2002) or altruism (Hochman and Rodgers 1974), the effect of narrowing income differentials on redistributional conflict and crime rates (Pauly 1973), on the equality of opportunities for future generations and to the standard Mirrlees (1971) optimal taxation argument for redistributional taxation as a type of social insurance, i.e., the maximizing of the expected utility of individuals ex ante, prior to knowing their future place in society. The motive we consider is also different from the motives of optimal taxation of families with or without household production as in Apps and Rees (1999a, 1999b, 2005), as they consider families that already exist. Schroyen (2003) also considers redistributive taxation in a setting of existing families, with a focus on arbitrage possibilities among family members. The benefits of redistributive income taxation occurs

\footnotetext{
${ }^{9}$ Families may also establish implicit contracts or explicit income sharing agreements for purposes of risk sharing, as has been discussed by (Anderberg 2001). Also from the point of view of individual perceptions, Pahl (1995) shows that, even though there is some heterogeneity within marriages about how partners perceive their incomes as private or joint family income, a large share of households simply pool all their income, and almost all households have some partial income pooling, and this essentially results in income sharing and equalization within the marriage.
} 
via its effects for the formation of families: matches with high match specific utility may not establish a relationship due to intra-family redistribution. Redistributive taxation reduces such redistributional concerns and this improves family formation for given match quality. This beneficial effect of income taxation is also quite different from the effects of taxation studied in the context of existing families which may be characterized by non-cooperative behavior inside the family. In this literature, it has been shown that taxes may affect inefficiencies from non-cooperation inside the family, as discussed in Konrad and Lommerud (1995) and in Anderberg and Balestrino (2003). These effects are absent in the analysis here, as, in order to remove such effects from the picture, we consider a framework in which all decisions on labor market effort inside the family are chosen fully efficiently, and we do not consider household production.

The notion that there are tendencies to positive assortative mating in the formation of households is central for the present analysis. Fernandez, Gul and Knowler (2005) confim this using data from 34 countries. Other work that present supportive evidence of positive assortative mating include for different precise definitions of inequality - Boulier and Rosenzweig (1984), Lam (1988) and Mare (1991). Aslaksen, Wennemo and Aaberge (2005) asks how the disequalizing contribution from women's income and the degree of assortative mating has evolved in Norway from 1973-1997. They find stronger evidence for assortative mating in the 1990s than in the 1980s - and in Norway the 1990s were a period where economic inequalities were on the rise in Norway compared to the decase before. Smith, Ultee and Lammers (1998) find an invered-U shape between positive marital sorting (according to education level) and some indicators for development. If one couples this with Kutzet's U, that suggests that inequality is largest for 'middle-layer' development countries, this translates to a statement that marital sorting is more segregated when inequality is larger. The authors argue that when societies become very developed, they also become quite complex, so people tend to meet in all sorts of contexts, and in particular, parental control is reduced. Even for the most developed countries there are considerable differences in the degree of homogamy, in that high inequality countries as the US has more homogamy than most countries in Europe (except some countries on the brim of the Mediterranien), with egalitarian Norway standing out as having little homogamy. There are, however, also cross-country differences that probably should be ascribed to cultural differences.

We proceed as follows. In section 2 we describe the set of players, their sets of actions, the timing of moves, and their payoffs. In section 3 we solve for the equilibrium in the absence of matching institutions, consider the welfare 
properties and how redistributive taxation affects welfare. In section 4 we consider the role of institutions that improve matching along the two different dimensions by which individuals differ in our framework. Section 5 discusses uncertainty of the quality of a match at the point of possible marriage and introduces a divorce option. Section 6 concludes.

\section{The matching framework}

We consider a set $I=[0,1]$ of individuals which is divided into two sets of equal size, denoted as $I_{M}$ and $I_{F}$. Individuals $i \in I$ have two characteristics, denoted by $w_{i} \in[0, \bar{w}]$ and $b_{i} \in[0, b]$. The first characteristic can be seen as $i$ 's wage rate in a perfectly competitive labor market. Together with an endogenous labor supply decision $z_{i} \geq 0$ the labor market productivity will determine gross labor income $z_{i} w_{i}$ for individual $i$. The second characteristic $b_{i}$ describes the individual's preferences and emotional predispositions along a one dimensional preference space. ${ }^{10}$ This characteristic will be important for the non-monetary emotional benefits from marriage. The decision problem whether or not to marry, and what this characteristic implies more precisely if two individuals do marry, will be described later. In addition, there is a welfarist government that may choose some institutional variables. The individuals $i \in I$ and the welfarist government are the players in a game with four stages that is described as follows.

In Stage 1, the welfarist government chooses a linear income tax from the set of proportional taxes with rates $t \in[0,1)$. It commits to redistributing all tax revenue that may accrue on a per capita basis equally to all individuals. The tax applies to all individuals, irrespective of their marital status. ${ }^{11}$ We restrict the instruments of the government to just this one, even though other instruments that affect the marriage decision may exist. Three reasons motivate this restriction. First, redistributional income taxation is in any case in operation in all modern economies. We show that this institution may have an additional benefit that has so far been overlooked. Second, redistributive taxation is a fairly direct instrument, as it works directly on the source of inefficiency in marriage decisions. Third, other instruments may be difficult to

\footnotetext{
${ }^{10}$ One could, for instance, think of $b_{i}$ as being distributed on a unit circle to emphasize that the characteristic $b$ is not ordered in the sense of universally better or worse.

${ }^{11}$ Individual income taxation is the predominant rule in OECD countries. Only a few countries apply household income taxation. In many countries, however, there are some special provisions for whether individuals are married or not married, and we disregard these provisions here.
} 
implement or ineffective due to observability problems, they may cause additional transaction costs, and may often be inferior to income redistribution. ${ }^{12}$

In STAGE 2, each individual from $I_{M}$ is matched with one other individual from $I_{F}$ according to a matching mechanism that is common knowledge. We typically denote pairs of matched individuals as $(m, f)$. All individuals $i \in I$ learn their own labor market productivity $w_{i}$ and preference characteristic $b_{i}$ and that of their matched partner.

In STAGE 3, all pairs of matched individuals $(m, f)$ make their decisions about whether to agree to a marriage. If both $m$ and $f$ agree to marry, the marriage takes place. If at least one of them does not agree to marry, both stay single. ${ }^{13}$

In STAGe 4 all individuals choose their labor supply, which is denoted $z_{i} \geq 0$, earn labor gross market income $w_{i} z_{i}$, pay taxes $t_{i} w_{i} z_{i}$ and receive a government transfer $s$. Labor supply has an opportunity cost. We assume that the effort cost of labor is a quadratic cost function, $C_{i}\left(z_{i}\right)=z_{i}^{2} / 2$.

A person who is single bears the opportunity cost of his or her labor supply, receives her gross income, pays taxes and receives some governmental transfer $s$. Accordingly, her net income is

$$
x_{i}=\left(1-t_{i}\right) w_{i} z_{i}+s .
$$

The labor and consumption choices are more complex for married couples, and a full analysis needs to describe the labor choices and the intra-family distribution of consumption as a subgame. We do not formalize this subgame explicitly. We replace the respective subgame that emerged from such an analysis by an exogenous intra-family rule of labor supply and consumption choices. The outcome of this rule is as follows. Partners choose $z_{m}$ and $z_{f}$ to maximize joint surplus net of taxes,

$$
(1-t) w_{m} z_{m}+(1-t) w_{f} z_{f}-\frac{z_{m}^{2}}{2}-\frac{z_{f}^{2}}{2}+2 s
$$

\footnotetext{
${ }^{12}$ For instance, a marriage subsidy will also be claimed by people who are then a couple in a material sense if the true status of a marriage is not observable, or will induce people to marry who, from a welfare point of view, really should not marry.

${ }^{13}$ The search and matching process considered here is very simple, as each player is matched with one other player only once, and a player who does not marry the player he or she is matched with stays single. We expect that this simplification that does not allow repeated matching does not affect our results qualitatively. In particular, this simple framework can be seen as the limiting case of standard search and matching models in which the future is highly discounted. The decision framework here could be embedded into a standard search and matching model as in Burdett and Coles (1999). In this case, the reservation utilities of $i$ of being singe forever are to be replaced by the equilibrium continuation value of a person who is single and waits for the next match.
} 
We note that the outcome in (2) can be microfounded within an approach that considers the family as a cooperative bargaining framework with noncooperative threat points. ${ }^{14}$ Perfectly egalitarian consumption inside the marriage is clearly a benchmark, but some amount of redistribution inside a marriage is sufficient to reproduce our results qualitatively in a more generalized context, and such redistribution has been found in a number of studies on non-cooperative families or on cooperative families with non-cooperation as the threat point of cooperative bargaining. ${ }^{15}$ Net of tax income $(1-t) w_{m} z_{m}+$ $(1-t) w_{f} z_{f}$ is shared equally between $m$ and $f$, such that consumption is

$$
x_{m}=x_{f}=(1-t) \frac{w_{m} z_{m}+w_{f} z_{f}}{2}+s,
$$

and each individual $i$ bears his or her own cost of labor effort $C_{i}\left(z_{i}\right)=z_{i}^{2} / 2$.

As can be seen from (3), the amount of intra-family income redistribution is considerable here. It is important to emphasize that any alternative assumption that has considerably less, but some income redistribution inside the family will generate qualitatively similar outcomes, as the same, but possibly smaller externality is at work when individuals make their decisions.

Turn now to the players' objective functions. We assume that a player $m$ who is matched with player $f$ has a payoff

$$
u_{m}=x_{m}-C_{m}\left(z_{m}\right)+\Phi_{m} \beta_{m f} .
$$

Here, $\Phi_{m}$ is an indicator function that takes on value $\Phi_{m}=1$ if $m$ is married to player $f$, and $\Phi_{m}=0$ if $f$ is single, and $\beta_{m f}$ is the emotional benefit that each partner obtains in the marriage. The size of this benefit depends on $b_{m}$ and $b_{f}$. The utility of individuals $f \in I_{F}$ that are matched with $m \in I_{M}$ is defined analogously. We denote the emotional benefit from marrying that each member of the match $(m, f)$ has as a function

$$
\beta_{m f}=\beta\left(b_{m}, b_{f}\right)
$$

Its value can be positive or negative and is maximal and equal to some $\beta^{*}>$ 0 if $b_{m}=b_{f}$, and typically diminishes as a function of the 'emotional and

\footnotetext{
${ }^{14}$ The most simple framework that yields this outcome has all consumption inside the marriage a pure public good, with cost of producing each unit of this public consumption good being two times the unit cost of consumption goods for single households, and efficient bargaining inside the marriage that causes efficient labor choices (see the Appendix for details).

${ }^{15}$ See, for instance, Konrad and Lommerud (1995, 2000) Lundberg and Pollak (1993, 2003) and Konrad, Künemund, Lommerud and Robledo (2002).
} 
preference distance' $\left|b_{m}-b_{f}\right|$ between $m$ and $f$. However, we need not specify the function $\beta$ more precisely, but consider distributions $H(\beta)$ of $\beta_{m f}$ directly, with support $\left[\beta, \beta^{*}\right]{ }^{16}$

We assume that the emotional benefit is symmetric $\left(\beta_{m f}=\beta_{f m}\right)$. This is not necessarily the case. We also considered the case in which $\beta_{m f}=$ $\beta\left(b_{f}\right)$, and $\beta_{f m} \equiv 0$. In this case, the marriage is a contract in which one side may buy 'love' from the other side, and this also has interesting features and implications for the desirability of redistributive taxation. Yet another alternative assumption would be that the second characteristic, and the family members' benefits from it, are related to non financial qualities of the potential partner which are sorted along a cardinal or ordinal scale (e.g., Anderberg 2004). Educational background or genetic fitness could be such qualities, and perhaps even beauty, which some people try to measure on a scale from 1 to 10 . We consider preference complementarities on qualities which do not have such a universally agreed ordinal property. If $b$ were simply a universally agreed, ordered qualities, these would essentially introduce a second quality dimension, much like productivity $w$, and one partner with high earnings ability may simply 'buy' a partner with high qualities along these other dimensions. Here we assume that the emotional rent from marriage is not related to such an ordinal quality dimension. One person is not universally superior to another person along this second dimension. Instead, the emotional rent accrues from a 'good match' in terms of similarity or preference congruence, for instance in terms of sharing the same sense of humour, similar preferences for food, for climate, for travelling, for the type of holiday, and other jointly consumed goods, or emotions that are difficult to trace or to specify much further, such as love and sympathy.

Utility in (4) is linear in consumption ${ }^{17}$. The cost of labor effort enters negatively, and the emotional rent from marriage enters additively, provided that $i$ is married. Finally, the government's objective function is the aggregate

\footnotetext{
${ }^{16}$ Happiness studies suggest that, on average, the emotional rents from marriage are quite high among married couples. Clark and Oswald (2002) estimate the average rent to be GBP 70000 per annum. The estimate by Blanchflower and Oswald (2004) is USD 100000 per annum. This is for all still existing marriages, so rents from a good match should be even larger.

${ }^{17}$ We make the assumption of linear utility of consumption utility not only for simplicity, but also because we want to isolate the additional motivation for redistributive income taxation analysed in this paper from other motivations that have been discussed elsewhere. In particular, this assumption removes the classical Mirrlees (1971) motive for redistributive taxation from the picture that a welfarist government may otherwise have.
} 
welfare of the set of individuals, which is defined as

$$
\Omega(t)=\int_{i \in I} u_{i} d i
$$

Note that, given that individuals do not yet know their own labor market productivities and preference characteristics at stage 1 and if these are drawn from the same distribution for them, invoking the usual 'veil of ignorance' argument, (6) can also be interpreted as the expected utility of individual $i$ at stage 1 , turning the choice of the optimal tax rate into an efficiency problem.

\section{Equilibrium and welfare}

Consider Stage 4. Individuals $i$ are either single or married to another individual.

A single person A single person has the payoff $u_{i}=(1-t) w_{i} z_{i}+s-z_{i}^{2} / 2$. The optimal effort choice determined from the first-order condition is $(1-$ t) $w_{i}=z_{i}$. Inserting this effort into the utility equation and simplifying yields

$$
u_{i}=\frac{(1-t)^{2} w_{i}^{2}}{2}+s
$$

Inside the married family According to the description of intra-family production and distribution, the spouses maximize (2). This yields efficient choices of effort $z_{m}=(1-t) w_{m}$ and $z_{f}=(1-t) w_{f}$. As the family income is shared, this yields identical incomes $y_{m}=y_{f}=(1-t)^{2}\left(w_{m}^{2}+w_{f}^{2}\right) / 2+s$ for both partners. Moreover, $i=m, f$ bear their own costs of effort equal to $(1-t)^{2} w_{i}^{2} / 2$, respectively. ${ }^{18}$ As described in (4), the partners in a marriage also enjoy some (possibly negative) rent from being together, that depends on $b_{m}$ and $b_{f}$ in the way described by (5).

For given $\left(w_{m}, w_{f}, b_{m}, b_{f}\right)$ we now can state the equilibrium intra-family utility of $m$ and $f$, which consists of their respective income shares after taxes

\footnotetext{
${ }^{18}$ This, plus the absence of scale economies from teaming up in a family simplify much of the analysis. Together these assumptions make the efficient labor choices independent of marital status, and this also makes the government budget independent of marital status. This helps to isolate the effect of taxation and matching institutions. Alternative assumptions about the family yield qualitatively similar results as regards the desirability of redistributive taxation, but additional effects blur the picture. For instance, scale economies of consumption inside the family or non-cooperative labor choices inside the family are interesting modifications that could be considered.
} 
and redistributions, minus their own cost of labor effort, plus their own emotional rent from this marriage. After consolidation of some terms, this utility becomes

$$
u_{m}=(1-t)^{2} \frac{w_{f}^{2}}{2}+s+\beta_{m f} \text { and } u_{f}=(1-t)^{2} \frac{w_{m}^{2}}{2}+s+\beta_{m f} .
$$

Note that $m$ 's payoff is a function of $f$ 's labor market productivity and vice versa. This is due to the effect that both partners choose their workload efficiently, bear their own cost of this workload, but share their total monetary income. If, for instance, $w_{f}<w_{m}$, then $m$ will end up being worse off than $f$ if they are married to each other. ${ }^{19}$

The government's budget All individuals work efficiently in the equilibrium of the subgame in STAGE 4 . As tax revenue is redistributed in a lump-sum fashion, we have

$$
s=t(1-t) \int_{i \in I} w_{i}^{2} d i=t(1-t) E\left(w_{i}^{2}\right) .
$$

The assumptions about efficient effort choices inside the family make the value of $s$ independent of whether individuals marry or not here, which simplifies the analysis.

Marriage choices Consider Stage 3. When individuals decide whether to agree to a marriage with their randomly matched partner, they compare the equilibrium utility they receive from STAGE 4 if they stay single with their equilibrium utility from marrying. Both persons need to agree to a marriage. A comparison reveals that (8) is at least as high as (7), and, hence, both $m$ and $f$ weakly prefer to marry if, and only if,

$$
\beta\left(b_{m}, b_{f}\right) \geq(1-t)^{2} \frac{\left|w_{m}^{2}-w_{f}^{2}\right|}{2} .
$$

Intuitively, as both individuals have the same emotional benefit from marriage and both individuals choose an efficient amount of labor but share

\footnotetext{
${ }^{19}$ For our main result it is not essential that the more productive person ends up being worse off than the less productive person. It is sufficient that there is some redistribution between male and female inside the family. However, the feature in (8) is quite typical for situations with incomplete contracts, with private provision to a public good playing an important role.
} 
their net-of-tax incomes inside a marriage and not outside a marriage, the more productive individual has the strictly lower benefit from marriage.

Note that $\left|w_{m}^{2}-w_{f}^{2}\right|$, and not the individual values $w_{m}$ and $w_{f}$ determine whether a marriage takes place. We therefore simplify notation by defining

$$
\omega_{m f} \equiv\left|w_{m}^{2}-w_{f}^{2}\right| .
$$

The distribution of male and female wages and the matching process between them together imply a distribution of wage differences $\omega_{m f}$, and we denote by $G(\omega)$ the cumulative distribution function of $\omega_{m f}$ with support $[\underline{\omega}, \bar{\omega}]$. Condition (10) and (11) directly yield the following result:

Proposition 1 For any $\omega_{m f}$, there is a critical

$$
\hat{\beta}\left(\omega_{m f}\right)=\frac{\omega_{m f}(1-t)^{2}}{2} .
$$

such that a marriage takes place if $\beta_{m f} \geq \hat{\beta}\left(\omega_{m f}\right)$. This $\hat{\beta}\left(\omega_{m f}\right)$ is increasing in $\omega_{m f}$, non-increasing in $t \in(0,1)$ and strictly decreasing in $t \in(0,1)$ if $\omega_{m f} \neq 0$.

For given distributions $H(\beta)$ of $\beta_{m f}$ and $G(\omega)$ of $\omega_{m f}$, an increase in the tax rate will generally increase the range of possible matches for which marriage takes place. Intuitively, the more productive person in a match is decisive for whether a marriage takes place. The redistributional sacrifice which the more productive person has from entering into a marriage with a less productive person is smaller the higher the redistributive tax rate, and this makes it more likely that the emotional benefit from marrying is higher than the sacrifice from intra-family redistribution.

Before turning to solving the game, in what follows we make two reasonable assumptions about the support $\left[\beta, \beta^{*}\right]$ of the distribution of $\beta$ that simplify notation. The first assumption is that $\underline{\beta} \leq 0$. This assumption suggests that marriage between some people can generate a negative emotional surplus. This seems very plausible. Second, we assume that the maximum possible emotional benefit from marriage is very high. More precisely, we assume that

$$
\beta^{*}>\frac{\bar{\omega}}{2} \text {. }
$$

From Proposition 1 it follows that this assumption will be sufficient for what could be called the possibility of Cinderella marriages: the maximum possible emotional benefit from marriage is so high that, if two persons obtain this highest possible emotional benefit from marrying, they always marry, regardless 
of the income disparity between them. Cinderella outcomes may be rare, but even the most extreme redistributional implications of marriage sometimes do not prevent it from happening. Note that both assumptions are for notational convenience only, unless the distributions $G(\omega)$ and $H(\beta)$ are further specified: if Cinderella outcomes were to be ruled out or if negative emotional benefits were to be ruled out for the feasible set of matches, instead of imposing such restrictions on the support of $\beta$, the probability mass on such outcomes can be arbitrarily close to zero.

We turn to STAGE 1 and ask what is the optimal tax from the perspective of a benevolent government which knows the distributions of $w_{i}, \omega$ and $\beta$ and maximizes (the expectation of) the welfare function (6). Making use of the equilibrium behavior in the subgame in stages 2-4, if $G(\omega)$ and $H(\beta)$ are absolutely continuous, this objective function can be written as

$$
\begin{aligned}
\Omega(t)= & \int_{i \in I} \frac{(1-t)^{2} w_{i}^{2}}{2} d i+\int_{i \in I} t(1-t) w_{i}^{2} d i \\
& +2 \int_{i \in I_{M}} \int_{0}^{\bar{\omega}} G^{\prime}(\omega) \int_{\hat{\beta}(\omega)}^{\beta^{*}} \beta H^{\prime}(\beta) d \beta d \omega d i \\
= & \frac{1-t^{2}}{2} E w_{i}^{2}+\int_{0}^{\bar{\omega}} G^{\prime}(\omega) \int_{\frac{\omega(1-t)^{2}}{2}}^{\beta^{*}} \beta H^{\prime}(\beta) d \beta d \omega
\end{aligned}
$$

All incomes net of taxes and all effort cost in the equilibrium can simply be added, and this yields the first integral term in the first line of (14). The second integral describes the expected tax revenue that is redistributed to the individuals, which is also independent of the actual distribution of incomes and matches. The third integral describes the expected emotional rents that accrue from marriage decisions. In any matched pair $(m, f)$, the emotional rents $\beta_{m f}=\beta_{f m}$ are the same for both individuals. Therefore, it is sufficient to sum up the expected emotional rents for all individuals in $I_{M}$, and to multiply them by 2 . Integrating the expected emotional rents for all individuals $m \in I_{M}$ takes into consideration that the emotional rent that accrues to an individual depends on whether the individual will end up in a marriage, and from the size of the emotional rent given that the individual ends up being married. We also use the assumption (13) which implies that $\min \left\{\underline{\beta}, \frac{\omega(1-t)^{2}}{2}\right\}=$ $\frac{\omega(1-t)^{2}}{2}$, simplifying this expression. The second equation in (14) uses that the aggregate expected utility is equal to the expected utility of a randomly chosen individual $i \in I$ by the fact that $I=[0,1]$ has unit measure.

We note:

The introduction of a small income tax is (weakly) welfare enhancing. 
Proof. The result follows from

$$
\frac{\partial \Omega}{\partial t}_{\mid t=0}=0+\int_{0}^{\bar{\omega}} \frac{\omega^{2}}{2} G^{\prime}(\omega) H^{\prime}\left(\frac{\omega}{2}\right) d \omega \geq 0 .
$$

Intuitively, the introduction of a small tax causes a tax distortion in the labor market, but starting from $t=0$, this distortion is of a magnitude that is a second-order one. However, the tax will induce all pairs of individuals to marry who had just been indifferent, given $t=0$. This typically is a first-order effect. Note that the same reasoning applies if the intra-family redistribution follows a different pattern: as long as marriage of individuals with different economic background will induce some income redistribution between these individuals that cannot be fully controlled by marriage contracts, this redistribution may prevent marriages that, seen from a welfare perspective, should take place.

As $\Omega^{\prime}(0) \geq 0$, if $\Omega(t)$ is a concave function in $t$, the optimal value of the tax rate is obtained by solving the first-order condition $\frac{\partial \Omega(t)}{\partial t}=0$, or

$$
t E w_{i}^{2}=\int_{0}^{\bar{\omega}} G^{\prime}(\omega) \frac{\omega(1-t)^{2}}{2} H^{\prime}\left(\frac{\omega(1-t)^{2}}{2}\right) \omega(1-t) d \omega .
$$

As the right-hand side of (16) is non-negative and generically positive and $E w_{i}^{2}>0$, the tax that is determined by this is non-negative and generically positive. We state this result as

Proposition 2 If $\Omega(t)$ is concave, the optimal linear tax is determined by (16).

The optimal linear tax is determined by the trade off between the increase in the loss from distortionary taxation of labor effort and the increase in expected emotional rent that is obtained from relaxing the incentive constraints (10) that need to be fulfilled for making a marriage individually rational from the perspective of the more productive individual in each match.

Proposition 3 reveals a new motivation for optimal redistributive income taxation: income redistribution and increased income equality is an inevitable consequence of marriage of individuals with different earning abilities. This property of marriage prevents some matched individuals from marrying, even though, from an efficiency point of view, they should marry. Redistributive taxation equalizes incomes independently of whether individuals marry, and this reduces the income equalizing effect of marriage. This increases the range of income differences along which marriage takes place. 
The motivation for redistributive taxation found here is independent from other welfarist motivations characterized earlier on that have been discussed in the introduction. In particular, risk aversion, insurance or the equalization of unequal marginal utilities of income as in the framework of optimal income taxation does not play a role here, as the individuals considered here are risk neutral.

In order to have a suitable criterion for comparing different matching regimes as regards the quality of matches they generate, and to do comparative static analysis along only one dimension, we will sometimes focus on the case in which the distributions $G(\omega)$ and $H(\beta)$ are uniformly distributed with densities $G^{\prime}=\gamma$ and $H^{\prime}=\phi$ on their respective supports, $[0,(1 / \gamma)]$ and $\left[\beta^{*}-(1 / \phi), \beta^{*}\right]$. The assumption $\beta \leq 0$ implies that $\beta^{*}-(1 / \phi) \leq 0$, and (13) implies that $\beta^{*}>1 /(2 \gamma)$ in this case.

The parametric case with uniform density is also suitable for showing that the assumptions for which the first-order condition $\Omega^{\prime}(t)=0$ determines the optimal tax are fulfilled for reasonable distributions. Inserting the uniform density into the welfare function (14), we obtain

$$
\Omega(t)=\frac{1-t^{2}}{2} E w_{i}^{2}+\gamma \phi \int_{0}^{(1 / \gamma)} \int_{\frac{\omega(1-t)^{2}}{2}}^{\beta^{*}} \beta d \beta d \omega .
$$

The density $H^{\prime}(\beta) \equiv \phi$ can be factored out here due to the assumptions about the supports of $\beta$ and $\omega$ that make sure that $\frac{\omega(1-t)^{2}}{2}>0 \geq \beta^{*}-\frac{1}{\phi}$ and that $\frac{\omega(1-t)^{2}}{2}<\beta^{*}$ for all $\omega$. From (17) we obtain

$$
\Omega(t)=\frac{1-t^{2}}{2} E w_{i}^{2}+\frac{1}{2} \phi\left[\left(\beta^{*}\right)^{2}-\frac{(1-t)^{4}}{12 \gamma^{2}}\right]
$$

Note that $\Omega^{\prime}(t)=-t E w_{i}^{2}+\frac{\phi}{2} \frac{4(1-t)^{3}}{12 \gamma^{2}}$. Hence, $\Omega^{\prime}(0)>0$ and $\Omega^{\prime \prime}(t)=-E w_{i}^{2}-$ $\frac{\phi}{2} \frac{(1-t)^{2}}{\gamma^{2}}<0$. Hence, the conditions as in Proposition 3 apply for this case, and the first-order condition determines the optimal tax, which is the implicit solution to

$$
\frac{t}{(1-t)^{3}} E w_{i}^{2}=\frac{\phi}{6 \gamma^{2}} .
$$

This condition can be used for the comparative statics when we consider and compare institutions that lead to different matching regimes. 


\section{Matching institutions}

So far we have assumed that the formation of pairs $(m, f)$ follows some exogenous matching process and that neither the government nor the individuals influence this process. However, the distributions $G(\omega)$ and $H(\beta)$ need not be exogenously given. Indeed, institutions exist that influence or determine $G(\omega)$ and $H(\beta)$.

Some institutions have a stronger impact on $H(\beta)$ than on $G(\omega)$. Free secondary and tertiary education, for example, will typically be used by almost all income groups, but each type of education will typically cluster individuals with specific preferences $b_{m} \approx b_{f}$. Similarly, there could be other institutions that sort individuals along their labor market productivities and yield matches with $w_{m} \approx w_{f}$. We will consider the implications of the different types of matching institutions for welfare and for the role of redistributive taxation that remains, given such institutions.

To allow for simple comparative static comparisons between matching institutions, we consider the case with $G(\omega)$ and $H(\beta)$ as uniform distributions with supports $[0,(1 / \gamma)]$ and $\left[\beta^{*}-(1 / \phi), \beta^{*}\right]$, respectively.

Preference matching institutions First we consider the implications of matching institutions that improve the matching of individuals as regards their preference congruence.

Proposition 3 An increase in $\phi$ (improved preference matching) implies a higher optimal tax rate.

Proof. Consider condition (19). The right hand side of (19) is monotonically increasing in $\phi$ and the left hand side is monotonically increasing in $t$. Accordingly, a higher $\phi$ implies that a higher optimal $t$ is required to equalize the two sides of equation (19).

Intuitively, the condition that determines the optimal $t$ balances the marginal welfare cost from labor market distortions from an increase in $t$ and the marginal benefits from more efficient marriage decisions. A change in $\phi$ does not change the marginal welfare cost that $t$ has on the labor market. However, the number of additional marriages induced by a marginal increase in $t$ is higher the higher the density of individuals who are marginally indifferent about whether or not to marry, and this density is monotonically increasing in $\phi$. Hence, the tax is more effective at the margin in making individuals marry if the love premium of marriage is less dispersed. Accordingly, if $H^{\prime}(\beta)=\phi$ increases, then a given increase in taxes induces a larger share of matched people to marry. 
Proposition 4 also describes the implications of the formation of institutions that improve the preference matching in the matching process. Such institutions have a tendency to make a higher redistributional tax rate optimal. For a given income heterogeneity that results from the matching mechanism, better preference matching may induce a higher redistributive tax rate.

Productivity matching institutions Next we consider institutions that improve the matching of individuals along the labor market productivity dimension. Let the actual distribution of productivities $w_{i}$ remain unchanged, such that $E w_{i}^{2}$ remains unchanged. Consider a change in the matching institutions, such that $G(\omega)$ changes. In particular, consider a change in matching institutions that reduces the dispersion of productivities of matched individuals.

Proposition 4 An increase in $\gamma$ (improved income matching) decreases the optimal redistributive tax.

Proof. Consider (19). The right-hand side of this expression is decreasing in $\gamma$ and independent of $t$. The left-hand side of (19) is increasing in $t$. Accordingly, an increase in $\gamma$ implies a decrease in $t$.

Intuitively, a higher $\gamma$ means that productivities of matched individuals are already more compressed. This makes further compression by an increase in the redistributive tax rate less effective.

The choice of matching institutions Propositions 4 and 5 suggest that there is some complementarity between redistributive taxation and institutions that improve preference matching and some substitutability between redistributive taxation and institutions that improve income matching. An important example is tracking in the education system. Such systems also sort individuals into different types of school as a function of their performance/ability measures when the tracking occurs. If there is a correlation between their relative performance/ability measures at this point and their later relative performance/ability, then tracking generates groups that are more homogenous in their productivities. If matching is more likely for individuals inside such groups than across groups, a tracking system can be a means that may make redistributive taxation less important as a means for overcoming the inefficiency in marriage decisions. ${ }^{20}$

\footnotetext{
${ }^{20}$ Via its impact on individual productivities, tracking may also change the aggregate distribution of abilities/performance in the working population and may increase its dispersion. For the sake of the argument, we disregard this possibility here.
} 
Note, however, that the redistributional consequences of income matching institutions and of redistributive income taxation are very different. The institutions that improve matching along the income dimension will make matches likely in which $m$ and $f$ both have high income or both have low income. As discussed in the empirical analysis by Ermisch, Francesconi and Siedler (2006), this reduces intergenerational income mobility and social stratification. In contrast, redistributive taxation will generally reduce the income dispersion in the aggregate across individuals, and will increase the likelihood of intermarriage between social and income classes. This makes productivity matching institutions particularly attractive for highly productive persons. They improve the quality of the match, they reduce the optimal redistributive tax. Broadening the perspective beyond the narrow limits of our formal framework, income matching institutions may also have an impact on the intergenerational transmission of the income distribution: such institutions make it more likely that the rich marry the rich and the poor marry the poor, and, in addition, reduce the amount of optimal redistributive taxation. Accordingly, income matching institutions reduce the importance of intermarriage as a source of intergenerational income mobility, and this effect is reinforced by the impact of such institutions for the optimal amount of redistributive taxation.

One may also consider individuals' incentives for making use of matching institutions as a function of their earnings abilities and their specific preferences. Individuals with very different incomes may consider marrying if their emotional premium from preference complementarities is sufficiently high. This result is robust to more general settings in which individuals who do not marry in a particular match are matched with other partners in the future, provided that the next match occurs only after a considerable amount of time, or if the intertemporal discount rate is high. The willingness of individuals with different incomes to marry benefits low income earners more than high income earners. Accordingly, individuals with high income earning abilities may prefer to use institutions that improve matching along the earning abilities dimension, whereas individuals with low income earning abilities may prefer to use institutions that improve matching along the emotional/preference matching dimension. This self selection into matching institutions as a function of own earnings abilities itself works as a matching device and if we observe more income heterogeneity in clubs or associations which cater to very specific preferences, could explain why we may observe fewer preference unspecific associations or clubs for low income groups, and why we may observe unspecific associations with very high membership fees.

Such self-selection into matching institutions also has some impact as 
regards the distribution of emotional rents in a society. If individuals with high earning abilities predominantly use matching institutions that sort along earning ability, they have a tendency for marrying even if the emotional rent from marriage is small. Individuals with low earning abilities may predominantly use matching institutions that sort along the preference congruence dimension, and this implies that they are more likely to have high emotional rents when they marry.

\section{Love uncertainty and the divorce option}

So far we have assumed that the marriage decision is irreversible. In such a context, when individuals decide whether or not to marry what matters for the decisions of individuals in a given match are the expectations of $\beta$ and $\omega$. Whether $\beta$ and $\omega$ are deterministic and fully known at the point of marriage or whether they are random variables with known distributions is not crucial for their marriage decision: individuals ask whether their expected emotional rent from marriage plus the implications of intra-marriage redistribution adds up to something positive.

More recently, work by Anderberg (2001), Rasul (2005), Brien, Lillard and Stern (2006) and Chiappori and Weiss (2006) and others consider the role of divorce for marriage decisions, particularly in matching frameworks. They highlight the fact that the quality of a match may be revealed only over time or may change during the marriage. Taking into account that individuals can divorce, the incoming information about the quality of a match becomes important and changes the decision problem in our framework also. Essentially, marriage in a situation in which the actual quality of the match is still uncertain gives the individuals who marry an option value. If the marriage turns out to imply a high emotional rent, they continue to stay together. If not, the more productive person who suffers from the intra-marital income distribution may desire a divorce, provided that the transaction cost of divorce is not too high, and assuming that divorce can be forced by a unilateral decision.

Chiappori and Weiss (2006) focus on the beneficial effects of higher divorce rates that work via their beneficial effects regarding the matching problem with respect to remarriage. We do not allow for rematching and remarrying, but we consider how the option of divorcing at a given cost influences the decision trade-off of the more productive person who has to share part of his/her income if he/she wants to enjoy the emotional rents from the marriage.

To study the implications of a divorce option, we modify and expand the 
framework. First, at the point when two matched individuals have to decide whether to marry, they know that their actual productivities $w_{m}, w_{f}$ and match specific quality $\beta_{m f}$ are random variables with cumulative distribution functions $W_{m}, W_{f}$ and $B_{m f}$. The actual values of $w_{m}, w_{f}$ and $\beta_{m f}$ are revealed right after the decision whether or not to marry. Second, at a new decision STAGE 3A each individual can bring about a divorce by deciding to terminate the marriage right after they have learned the actual values of $w_{m}, w_{f}$ and $\beta_{m f}$. After a divorce, each of them will pursue their lives as singles and will not have an opportunity to remarry.

The divorce also imposes some cost on each of them, and this divorce cost is denoted as $\delta \geq 0$. A narrow interpretation of this cost is simply the transaction cost of splitting up the family, dividing the household, or the additional transaction cost in the context of child raising. Alimony is, in principle, a different issue, but the results we have are also indicative for the role of alimony. Such payments are typically made by the high income earner to the low earner, i.e., they are a cost of divorce for the high income earner (but not for the low income earner). Now, in our decision framework the high income earner is the one who decides both whether the marriage takes place or whether to divorce. Whether or not the low income earner also has a divorce cost is not important in this case.

Uncertain emotional rents We concentrate on the case in which labor market productivity is deterministic at the stage when individuals are matched and it is common knowledge, and where only the emotional rent $\beta_{m f}$ is a non-degenerate random variable when players decide about whether to marry. The consideration of uncertain labor market productivities is also interesting, but more complex, as uncertainty about $\omega_{m f}$ is typically not feasible without uncertainty about $w_{m}$ and $w_{f}$, and the relationship between the two will generally depend on the matching process that has been considered as a black box here. To deal with uncertain labor market productivities will typically require opening up this black box, and we defer this to future research.

Note that the decision making of STAGE 4 remains the same as in section 3 , given that an individual is single or married. However, if individuals reach this stage after divorcing, their payoff is reduced by the divorce $\operatorname{cost} \delta$, compared to reaching this stage as a person who has never married. Turn now to STAGE $3 \mathrm{~A}$, between STAGE 3 and Stage 4 . If an individual $m$ or $f$ is single at this stage, the individual has nothing to decide. Suppose, instead, an individual $m$ is married to another individual $f$, and let $w_{m} \geq w_{f}$. Whether they stay married or choose to divorce depends on a condition that is similar 
to (12). They continue as a married couple if

$$
\beta_{m f}+\delta \geq(1-t)^{2} \frac{\left|w_{m}^{2}-w_{f}^{2}\right|}{2}=(1-t)^{2} \frac{\omega_{m f}}{2} .
$$

Divorce occurs otherwise.

Turn now to the STAGE 3 at which $m$ and $f$ are matched and decide about whether to marry. The payoff of $m$ from not marrying is given in (7). The expected payoff for $m$ from marrying is

$$
\begin{aligned}
& B_{m f}\left((1-t)^{2} \frac{\omega_{m f}}{2}-\delta\right)\left[\frac{(1-t)^{2} w_{m}^{2}}{2}-\delta\right] \\
& +\left(1-B_{m f}\left((1-t)^{2} \frac{\omega_{m f}}{2}-\delta\right)\right) \frac{(1-t)^{2} w_{f}^{2}}{2} \\
& +\int_{(1-t)^{2} \frac{\omega_{m f}}{2}-\delta}^{\beta^{*}} \beta B_{m f}^{\prime}(\beta) d \beta+s .
\end{aligned}
$$

Accordingly, the expected net benefit of marrying for player $m$ can be denoted as the difference between (21) and (7), which reduces to

$$
\left(1-B_{m f}(\hat{\beta})\right)\left(w_{f}^{2}-w_{m}^{2}\right) \frac{(1-t)^{2}}{2}-\delta B_{m f}(\hat{\beta})+\int_{\hat{\beta}}^{\beta^{*}} \beta B_{m f}^{\prime}(\beta) d \beta
$$

with $\hat{\beta}\left(t, \omega_{m f}, \delta\right)=(1-t)^{2} \frac{\omega_{m f}}{2}-\delta$. The first term in $(22)$ is non-negative for player $f$ and non-positive for $m$, and this second player is decisive for whether the marriage takes place, and whether the marriage is sustained or the couple are divorced.

The analysis for player $f$ is fully analogous and the expected benefit for $f$ is obtained by replacing $m$ and $f$ in (22).

If $\delta$ is very high, divorce is prohibitively expensive. The problem becomes equivalent to the problem in sections 2 and 3 without divorce, with

$$
E \beta_{m f}=\int_{\underline{\beta}}^{\beta^{*}} \beta B_{m f}^{\prime}(\beta) d \beta
$$

replacing the deterministic $\beta_{m f}$ in the analysis in sections 2 and 3 .

If $\delta$ is zero, then the marriage will always take place. The situation is also equivalent to the problem in sections 2 and 3, where STAGE $3 \mathrm{~A}$ is trivial (always marry) and the divorce stage plays the role of the marriage decision in section 3 , and is based on the same decision criterion as in section 2, where the 
continuation of marriage here is equivalent to the decision to marry in sections 2 and 3 , and where this decision is based on the ex post realized value of $\beta_{m f}$.

Suppose the divorce cost $\delta$ is positive, but not prohibitively high. In this case, the more productive person trades off the option value of marrying with the expected income sacrifice from marrying. An increase in $\delta$ will typically make marriage less likely, but more stable. The more productive individual is decisive. This individual's benefits from marrying and his/her utility in the state of marriage both weakly decrease in $\delta$. Assuming that $\beta \leq-\delta$, this can be seen from differentiating (22) with respect to $\delta$, as this yields

$B_{m f}^{\prime}(\hat{\beta})\left(w_{f}^{2}-w_{m}^{2}\right) \frac{(1-t)^{2}}{2}+\hat{\beta} B_{m f}^{\prime}(\hat{\beta})-B_{m f}(\hat{\beta})+\delta B_{m f}^{\prime}(\hat{\beta})={ }_{\text {if } w_{f}<w_{m}}-B_{m f}(\hat{\beta}) \leq 0$.

We summarize this as a proposition:

Proposition 5 An increase in the cost of divorce (weakly) decreases the more productive partner's expected benefit from marriage.

The welfare implications of divorce cost are indeterminate. To see this, we consider a simple example that reveals that divorce cost may increase or decrease welfare. Consider $\omega_{m f}=4, t=0$, and $\beta_{m f} \in\{1,10\}$ with probability $1-p$ and $p$, respectively, and compare the cases with divorce cost equal to $\delta=1.1$ and $\delta=0$.

For $\delta=0$, marriage takes place; a divorce occurs if, and only if, $\beta_{m f}=$ 1. Accordingly, the expected emotional rents sum up to $2 \times 10 p$.

For $\delta=1.1$, consider first the divorce behavior once $\beta_{m f}$ is known. If $m$ and $f$ did not marry, the expected emotional rents sum up to zero. If $m$ and $f$ married, then the marriage continues if $\beta_{m f}+\delta \geq \frac{\omega_{m f}}{2}$. Given the parameters in the example, the marriage is always sustained, even if $\beta_{m f}=1$, as $\beta_{m f}+\delta=2.1>2=\omega_{m f} / 2$. The expected emotional rents sum up to $2 \times(10 p+(1-p))$. Hence in this example the divorce cost increases welfare if the marriage takes place, and it decreases welfare compared to $\delta=0$ if the marriage does not take place. Note that $m$ agrees to marry $f$ if the ex ante benefit from marrying is positive, i.e., if the expected emotional rent exceeds the distributional cost, which is the case if $p \cdot 10+(1-p) \cdot 1 \geq 2$. Otherwise player $m$ does not want to marry $f$. The same applies for $f$ 's decision. Compared to $\delta=0$, a divorce cost of $\delta=1.1$ increases ex ante welfare if $p \geq 1 / 9$, and decreases ex ante welfare if $p<1 / 9$.

Consider now the implications of redistributive taxation for the decision to divorce, and for the decision to marry. Let $m$ be the decisive player in a given match $(m, f)$. Suppose first that $m$ with $w_{m}>w_{f}$ preferred to marry 
$f$. Then, the increased stability of this marriage is straightforward from the definition of the critical level of emotional rent $\hat{\beta}\left(t, \omega_{m f}, \delta\right)=(1-t)^{2} \frac{\omega_{m f}}{2}-\delta$, at which $m$ is indifferent whether to continue or to terminate the relationship. An increase in $t$ decreases the critical $\hat{\beta}$ for which $m$ is just indifferent between divorce or not; hence, an increase in $t$ stabilizes a marriage for given $w_{m}$ and $w_{f}$ with respect to the uncertainty of emotional rents from marrying. The same logic applies if $f$ is the decisive player.

Moreover, an increase in $t$ makes marriage more likely from an ex ante point of view. The net benefit of marriage that is obtained from a marginal increase in $t$ can be derived from (22) as

$$
\begin{aligned}
& \left(1-B_{m f}(\hat{\beta})\right)\left(w_{f}^{2}-w_{m}^{2}\right)(1-t) \\
& +\left[-B_{m f}^{\prime}(\hat{\beta})\left(w_{f}^{2}-w_{m}^{2}\right) \frac{(1-t)^{2}}{2}-\delta B_{m f}^{\prime}(\hat{\beta})-\hat{\beta} B_{m f}^{\prime}(\hat{\beta})\right] \frac{\partial \hat{\beta}}{\partial t} .
\end{aligned}
$$

Making use of $\hat{\beta}_{m f}=(1-t)^{2} \frac{\omega_{m f}}{2}-\delta$, the square bracket reduces to zero, such that the whole expression reduces to

$$
-\left(1-B_{m f}(\hat{\beta})\right)\left(w_{f}^{2}-w_{m}^{2}\right)(1-t),
$$

and this expression is positive given that $w_{f}<w_{m}$. We summarize this as

Proposition 6 Let $w_{m}>w_{f}$. For given divorce cost $\delta>0$, an increase in $t$ increases $m$ 's expected net benefit from a marriage and makes any given marriage more stable.

\section{Conclusions}

In this paper we uncover a new, and potentially important, efficiency reason for income redistribution: redistribution encourages people to marry if they are a good match in terms of their preferences and emotions but differ in their income earning abilities. Marriage involves some intra-family redistribution, particularly if the people who marry are very unequal in their income earning abilities or wealth. This may prevent people with different income from marrying, even if their emotional benefits from marrying were large, because the high income earner is concerned too much about sharing his or her income with the respective partner. From a social point of view, and from an ex ante efficiency point of view when individuals do not yet know their later productivities in life, only the emotional rent should count for whether a marriage should take place, whereas the income redistribution is essentially neutral from a welfare 
point of view (or may be even beneficial from such a point of view). Taxation reduces the inequality and this makes the emotional rent from marrying more important for the private decisions about whether to marry, and this improves the efficiency properties of marriage decisions.

We also consider how matching institutions affect the size of the optimal redistributive income tax. We find that matching institutions that make it more likely that individuals who are a good match in terms of their emotional and preference disposition are matched suggest an even higher optimal redistributive tax. Such institutions are complementary to redistributive taxation as a means of improving marriage decisions. In contrast, matching institutions that make it more likely that individuals with similar incomes are matched are substitutes for redistributive taxation. In existing societies both matching institutions and voters' preference for redistribution evolve over the long run. It is hard to say what governs these processes and what comes first and last. Our analysis indicates that very different societal situations can be optimal at the same time. In some societies, matching will typically be along the dimension of income. Redistribution is than less needed than with preference matching. Or, the other way around, with little redistribution there is much need for income matching institutions - for the sake of love. At the same time, other societies can have settled in a quite different equilibrium with much preference matching and much redistribution. As we have mentioned before, Clark and Oswald (2002) and Blanchflower and Oswald (2004) suggest that the avarage rent from an existing marriage is high and roughly the same in the US and the UK - even though matching institutions and the level of redistribution are likely to be different in the two countries. Nevertheless, given matching institutions, redistribution is good for love, but more so in societies with what we have called preference matching.

Finally we discuss the role of divorce in the present framework. Marriage is more likely if the cost of divorce is lower, but divorce rates will also be higher. The welfare implications of the cost of a divorce are not straightforward. Redistributive taxation has similar effects in a framework with a divorce option. It stabilizes marriage and makes marriage for a given match more likely.

We develop these results in a very basic matching framework and make some stylized assumptions about the way a marriage is organized. We expect that our results generalize qualitatively for more general frameworks. 


\section{Appendix}

We used a reduced form for describing the optimization problem within the family and assumed that the partners maximize joint surplus described by (2) that can be based on several microeconomic underpinnings. As an example, we sketch a possible microfoundation for the setup used in (2) in an infinitely repeated game as follows.

Consider the period game. Let the individual utility functions of single individuals be again be given by

$$
u_{i}=(1-t) w_{i} z_{i}+s-\frac{z_{i}^{2}}{2} .
$$

Single individuals then solve their maximization problem by $z_{i}^{*}=(1-t) w_{i}$, and pay taxes equal to $T_{i}=t(1-t) w_{i}^{2}$. This is also the outcome in each period if we consider an infinitely repeated game with discounting, and for a time invariant discount factor, the discounted present value of utility is obtained by multiplying this utility with $1 /(1-\delta)$.

Consider now a married couple. Assume that all income inside the family has to be used on non-exclusive, and non-rival public goods. This assumption implicitly rules out monetary transfers and compensation payments between spouses. Suppose further that each unit of these family public goods costs two units of private goods, which sterilizes against possible economies or diseconomies of scale. Accordingly, if $z_{m}$ and $z_{f}$ are the units of labor chosen by the spouses, the consumption term in their utility becomes

$$
x_{m}=x_{f}=(1-t) \frac{w_{m} z_{m}+w_{f} z_{f}}{2}+s,
$$

and their tax payments are $T_{m}+T_{f}=t w_{m} z_{m}+t w_{f} z_{f}$, respectively. Individual $m$ 's utility, hence, is

$$
u_{m}=\frac{x_{m}+x_{f}}{2}-\frac{z_{m}^{2}}{2}+\beta_{m f}
$$

Suppose first that $m$ and $f$ choose their labor efforts non-cooperatively. Individual maximization taking $z_{f}$ and $s$ as given, $m$ equalizes own individual marginal disutility of labor and own individual marginal consumption benefit from this effort; hence, $m$ chooses

$$
\hat{z}_{m}=(1-t) \frac{w_{m}}{2}
$$


and analogously for $f$. The resulting utilities from inserting $\hat{z}_{m}$ and $\hat{z}_{f}$ into (30) yield the period payoffs in the non-cooperative equilibrium as

$$
\hat{u}_{m}=\frac{(1-t)^{2} \frac{w_{m}^{2}}{2}+(1-t)^{2} \frac{w_{f}^{2}}{2}+2 s}{2}-(1-t)^{2} \frac{w_{m}^{2}}{8}+\beta_{m f}
$$

and analogously for $\hat{u}_{f}$.

Family utility in each period is maximized for a combination of $z_{m}$ and $z_{f}$ that maximizes $u_{m}+u_{f}$, and the respective values of work efforts are $z_{m}^{*}=(1-t) w_{m}$ and $z_{f}^{*}=(1-t) w_{f}$. They co-incide with the work effort chosen by singles, because, by construction, the higher price of family goods just compensates for the effect of non-rivalry in consumption. The resulting utilities are

$$
u_{m}^{*}=\frac{(1-t)^{2} w_{m}^{2}+(1-t)^{2} w_{f}^{2}+2 s}{2}-(1-t)^{2} \frac{w_{m}^{2}}{2}+\beta_{m f},
$$

and analogously for $f$.

Whether this efficient outcome can be reached inside the family and without side payments in an infinitely repeated game with a Friedman equilibrium (i.e., with Nash reversion punishment) depends on whether the utilities reached for $z_{m}^{*}$ and $z_{f}^{*}$ are at least as high as $\hat{u}_{m}$ and $\hat{u}_{f}$ for both spouses and on the size of the discount factor $\delta$. Comparing the utility difference, $u_{i}^{*}-\hat{u}_{i}>0$ for both $i=m, f$, if

$$
\frac{w_{f}^{2}}{2}<w_{m}^{2}<2 w_{f}^{2} .
$$

As the individual gain from unilaterally deviating from the cooperative equilibrium in one period is finite, it follows from straightforward reasoning that the efficient choices of labor input can be supported as a Friedman equilibrium of an infinitely repeated game if the discount factor $\delta$ is sufficiently close to 1 .

\section{References}

[1] Alm, James, and Leslie A. Whittington, 1995, Income taxation and the marriage decision, Applied Economics, 27, 25-31.

[2] Anderberg, Dan, 2001, An equilibrium analysis of marriage, divorce and risk sharing, CESifo Working Paper No. 555.

[3] Anderberg, Dan, 2004, Getting hitched: the equilibrium marriage market behavior of a British cohort, mimeo. Royal Holloway University of London. 
[4] Anderberg, Dan, and Alessandro Balestrino, 2003, Public spending with non-cooperative families, mimeo.

[5] Apps Patricia, and Ray Rees, 1999a, On the taxation of trade within and between households, Journal of Public Economics, 73 (2), 241-263.

[6] Apps Patricia, and Ray Rees, 1999b, Individual versus joint laxation in models with household production, Journal of Political Economy, 107 (2), 393-403.

[7] Apps, Patricia, and Ray Rees, 2005, Some extensions of the theory of optimal income taxation, mimeo., University of Munich.

[8] Aslaksen, Julie, Tom Wennemo, and Rolf Aaberge, 2005. 'Birds of a feather flock together': the impact of choice of spouse on family labor income inequality, Labour, 19 (3), 491-515.

[9] Becker, Gary S., 1981, A Treatise on the Family, Harvard University Press, Cambridge, MA.

[10] Bergstrom, Theodore, 1989, Puzzles - Love and Spaghetti, the opportunity cost of virtue, Journal of Economic Perspectives 3(2), 165-173.

[11] Blanchflower, David G., and Andrew J. Oswald, 2004, Well-being over time in Britain and the USA, Journal of Public Economics, 88 (7-8), $1359-1386$.

[12] Boulier, Bryan L., and M.R. Rosenzweig, 1984, Schooling, search, and spouse selection: testing economic theories of marriage and household behavior, Journal of Political Economy, 92, 712-732.

[13] Brien, Michael J., Lee A. Lillard, and Steven Stern, 2006, Cohabitation, marriage, and divorce in a model of match quality, International Economic Review, 47(2), 451-494.

[14] Burdett, Ken, and Melvyn G. Coles, 1999, Long-term partnership formation: marriage and employment, Economic Journal, 109, F307-334.

[15] Chiappori, Pierre-Andre, and Yoram Weiss, 2006, Divorce, remarriage, and welfare: a general equilibrium approach, Journal of the European Economic Association, 4 (2-3), 415-426. 
[16] Clark, Andrew E., and Andrew J. Oswald, 2002, A simple statistical method for measuring how life events affect happiness, International Journal of Epidemiology, 31, 1139-1144.

[17] Corneo, Giacomo, 2002, The efficient side of progressive income taxation, European Economic Review, 46 (7), 1359-1368.

[18] Edlund, Lena, 1999, Son preference, sex ratios, and marriage patterns, Journal of Political Economy, 107 (6), 1275-1304.

[19] Edlund, Lena, 2006, Marriage: past, present, future?, CESifo Economic Studies, 52 (4), 621-639.

[20] Ermisch, John, Marco Francesconi and Thomas Siedler, 2006, Intergenerational mobility and marital sorting, Economic Journal, 116, 659-579.

[21] Feenberg, Daniel R. and Harvey Rosen, 1994, Recent developments in the marriage tax, National Tax Journal, 48 (1), 91-101.

[22] Fernández, Raquel, Nezih Guner and John Knowles, 2005, Love and money: a theoretical and empirical analysis of household sorting and inequality, Quarterly Journal of Economics, 120 (1), 273-344.

[23] Hochman, Harold M, and James D. Rodgers, 1974, Redistribution and the Pareto criterion, American Economic Review, 64 (4), 752-757.

[24] Konrad, Kai A., and Kjell Erik Lommerud, 1995, Family policy with noncooperative families, Scandinavian Journal of Economics, 97, 581-601.

[25] Konrad, Kai A., and Kjell Erik Lommerud, 2000, The bargaining family revisited, Canadian Journal of Economics, 33(2), 471-487.

[26] Konrad, Kai A., Harald Künemund, Kjell Erik Lommerud and Julio Robledo, 2002, Geography of the family, American Economic Review, 92 (4), 981-998.

[27] Lam, David, 1988, Marraige markets and assortaive mating with household public goods: theoretical results and empirical omplications, Journal of Human Resources, 23, 462-487.

[28] Levine, Robert, Suguru Sato, Tsukasa Hashimoto and Jyoti Verma, 1995, Love and marriage in eleven cultures, Journal of Cross-cultural Psychology, $26(5), 554-571$. 
[29] Lundberg, Shelly, and Robert A. Pollak, 1993, Seperate spheres bargaining in the marriage market, Journal of Political Economy, 101 (6), 9881010 .

[30] Lundberg, Shelly, and Robert A. Pollak, 2003, Efficiency in marriage, Review of Economics of the Household, 1 (3), 153-167.

[31] Mare, Robert D., 1991, Five decades of educational assortative mating. American Journal of Sociology, 56, 15-32.

[32] Mirrlees, James, 1971, An exploration in the theory of income taxation, Review of Economic Studies, 38, 175-208.

[33] Pahl, Jan, 1995, His money, her money: recent research on financial organization in marriage, Journal of Economic Psychology, 16, 361-376.

[34] Pauly, Mark, 1973, Income redistribution as a local public good, Journal of Public Economics, 2, 35-58.

[35] Rasul, Imran, 2005, Marriage markets and divorce laws, Journal of Law, Economics and Organization, 22(1), 30-69.

[36] Schroyen, Fred (2003), Redistributive taxation and the household: the case of individual filings, Journal of Public Economics, 87, 2527-2547.

[37] Smits, Jeroen, Wout Ultee, and Jan Lammers, 1998, Educational homogamy in 65 countries: an explanation of differences in openness using country-level explanatory variables, American Sociological Review, 63, 264-285.

[38] Sprecher, Susan, Arthur Aron, Elaine Hatfield, Anthony Cortese, Elena Potapova and Anna Levitskaya, 1994, Love: American style, Russian style, and Japanese style, Personal Relationships, 1, 349-369.

[39] VG, 18.11.2007, Slik finner de rike sammen ('How the rich find together').

[40] Wong, Y. Linda, 2002, Structural estimation of marriage models, mimeo. 